\title{
Elastic buckling analysis of corroded stiffened plates with irregular surfaces
}

\author{
AHMAD RAHBAR-RANJI \\ Department of Ocean Engineering, AmirKabir University of Technology, \\ Hafez Ave., Tehran 15914, Iran \\ e-mail: rahbar@aut.ac.ir
}

MS received 25 October 2013; revised 4 August 2014; accepted 4 September 2014

\begin{abstract}
Numerical simulation is used to study the influence of corrosion damage in stiffened plates focusing on elastic buckling strength. Three-dimensional specta are used to simulate geometries of corroded surfaces and finite element method is employed for computing Euler stress of stiffened plates. The influence of corrosion patterns, amount of corrosion loss and roughness of surface are investigated. Ratio of Euler stress of corroded stiffened plate over Euler stress of un-corroded stiffened plate is used to characterize the effects of corrosion on reduction of buckling strength. Results show that reduction of buckling strength is very sensitive to the amount of corrosion loss and roughness of surface, but less sensitive to the location of corroded region. The potential for decrease in buckling strength as a consequence of corrosion is found to depend on the dominant buckling mode. Residual buckling strength is reduced by as much as $12 \%$ for the interaction of plate-web-torsional buckling mode, and by $2 \%$ for column buckling.
\end{abstract}

Keywords. Corrosion; irregular surfaces; stiffened panel; interaction of buckling modes.

\section{Introduction}

Stiffened plate, where thin plate stiffened with welded longitudinal stiffeners and transverse girders (figure 1), has been used as a main structural element in ship and offshore structures for their high strength-to-weight ratio. The primary function of stiffened plates is to support lateral loads imposed from weight of cargo or sea pressure, however, bending of ship hull girder induces in-plane loading as well.

Compressive longitudinal stresses produced by hull girder bending moment impose buckling of longitudinal stiffeners between two adjacent transverse girders. Depending on dimensions of stiffeners and attached plate, different modes of buckling from local buckling of plate or stiffeners to overall buckling of panel could occur. Stiffener buckling itself is divided into local buckling of web/flange, beam-column type flexural buckling and torsional buckling. Flexural and torsional buckling of stiffeners interact when asymmetric stiffeners are used. Interactions of plate-web-torsional buckling occur regardless of stiffeners type (figure 2). 


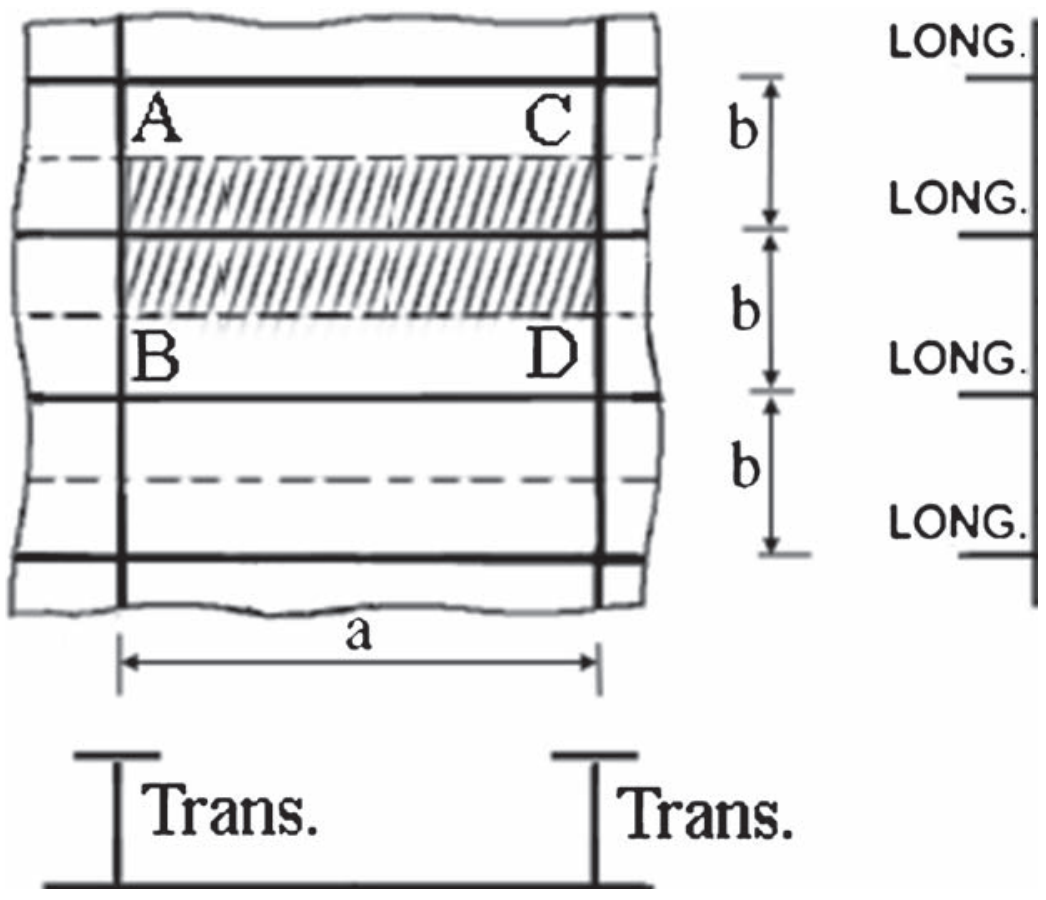

Figure 1. Description of stiffened plate and the extent of model considered for FEM.

Steel structures are prone to different time-dependent structural damages. Corrosion and fatigue cracks are of two types likely damages, and the likelihood of increase with the aging of structures. For the structural safety assessment of corroded structures, strength reduction should be determined as a function of time to plan repairs and replacements. Two main corrosion mechanisms, namely, general corrosion and pitting corrosion are recognized. General corrosion was principal type cited requiring extensive steel renewals every year in uncoated ballast tanks (SCC-394 1997).

Many research works are devoted on strength analysis of corroded plates. For example, Nakai et al (2006) have performed a series of nonlinear finite element analysis (FEA) to investigate

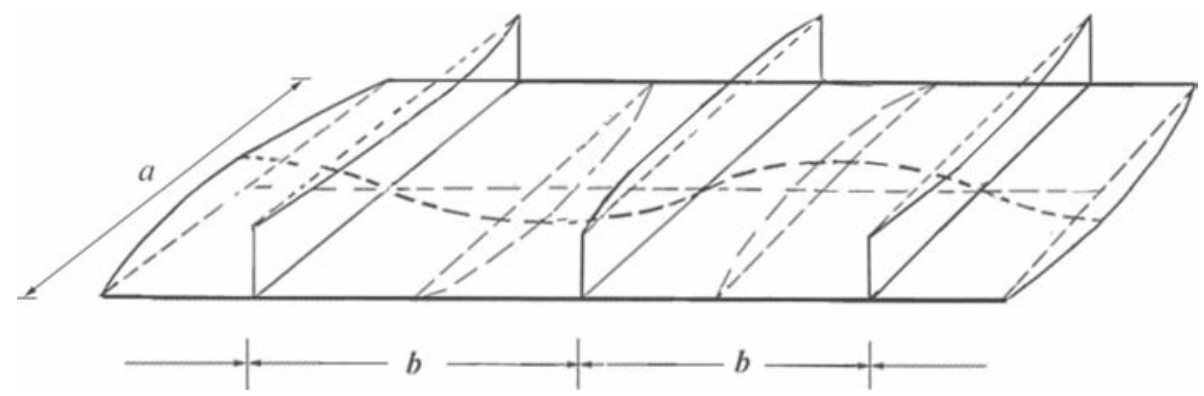

Figure 2. Buckling deformation of stiffened plate in plate-web-torsional mode. 
the strength of plates with pit corrosion subjected to in-plane compressive loads and bending moments. Some research studies have investigated detrimental effect of corrosion on elastic buckling of structures. Oszvald \& Dunai (2010) have studied experimentally and numerically buckling of corroded steel angle elements. Wang et al (2005) have reported buckling strength reduction of corroded deck plates in 20 years old ships under uniform longitudinal compression.

General corrosion, which occurs in relatively larger areas, yields irregular surfaces. Limited number of investigations have been done on time dependent surface geometry of plates due to corrosion. Rahbar-Ranji (2001) has proposed a spectrum for random simulation of geometry of corroded surface based on the mean and standard deviation of thickness diminution. RahbarRanji (2012a, b, 2013a, 2014a, b) has used this spectrum to analyse plastic collapse load, ultimate strength, elastic buckling strength of corroded plates and tripping analysis of corroded stiffeners with irregular random surfaces.

The main aim of the present work is to determine Euler stress of stiffened plates with both-sided corroded surfaces. Irregular surfaces are generated based on power spectrum of the corroded surface (Rahbar-Ranji 2001) and Euler stress is calculated using ANSYS code (version 5.6). Ratio of buckling strength of corroded plate over un-corroded plate is used as a measure of reduction of elastic buckling strength of corroded plate. The effects of different geometric and corrosion parameters on reduction factor are studied. Having this reduction parameter, buckling strength of corroded stiffened plates could be estimated as a function of corrosion degree.

\section{Geometry of corroded surface}

General corrosion develops in large areas and yields irregular surfaces with variable thickness. Rahbar-Ranji (2001) has proposed a spectrum for geometry of corroded surface as follows

$$
S(k)=\left\{\begin{array}{cc}
\frac{11.88 \alpha \beta \sigma}{k^{2}} \operatorname{Exp}\left[-\frac{2}{3}\left(\frac{\beta}{2.97 \sigma|k|}\right)^{3}\right] & \Delta t_{\text {avr }} \leq 2.97 \sigma \\
\frac{\alpha \beta\left(\Delta t_{\text {avr }}+2.97 \sigma\right)^{2}}{\Delta t_{\text {avr }} k^{2}} \operatorname{Exp}\left[-\frac{2}{3}\left(\frac{\beta}{\Delta t_{\text {avr }}|k|}\right)^{3}\right] & \Delta t_{\text {avr }} \geq 2.97 \sigma,
\end{array}\right.
$$

where $k$ is the wave number, $\Delta t_{a v r}$ and $\sigma$ are the average and standard deviation of the thickness diminution, and $\alpha$ and $\beta$ are two fitting constants which depend on the corrosion condition and $\alpha=0.01-0.15$ and $\beta=0.02-0.15$. Statistical features of surface irregularities can be characterized by Eq. (1) and also by the parameters $\alpha$ and $\beta$. By varying parameters of $\alpha$ and $\beta$, it is possible to have a wide range of family of spectrum (figure 3). As can be seen, the upper-cut-off wave number for the proposed spectrum is less than $1 \mathrm{rad} / \mathrm{mm}$.

Stochastic characteristics in all directions should be the same, since corrosion is a random phenomenon. Therefore, an isotropic three-dimensional spectrum is expressed as follows

$$
S\left(k_{1}, k_{2}\right)=\left\{\begin{array}{c}
\frac{11.88 \alpha \beta \sigma}{k_{1}^{2}+k_{2}^{2}} \operatorname{Exp}\left[-\frac{2}{3}\left(\frac{\beta}{2.97 \sigma \sqrt{k_{1}^{2}+k_{2}^{2}}}\right)^{3}\right] \quad \Delta t_{\text {avr }} \leq 2.97 \sigma \\
\frac{\alpha \beta\left(\Delta t_{\text {avr }}+2.97 \sigma\right)^{2}}{\Delta t_{\text {avr }}\left(k_{1}^{2}+k_{2}^{2}\right)} \operatorname{Exp}\left[-\frac{2}{3}\left(\frac{\beta}{\Delta t_{\text {avr }} \sqrt{k_{1}^{2}+k_{2}^{2}}}\right)^{3}\right] \Delta t_{\text {avr }} \geq 2.97 \sigma .
\end{array}\right.
$$




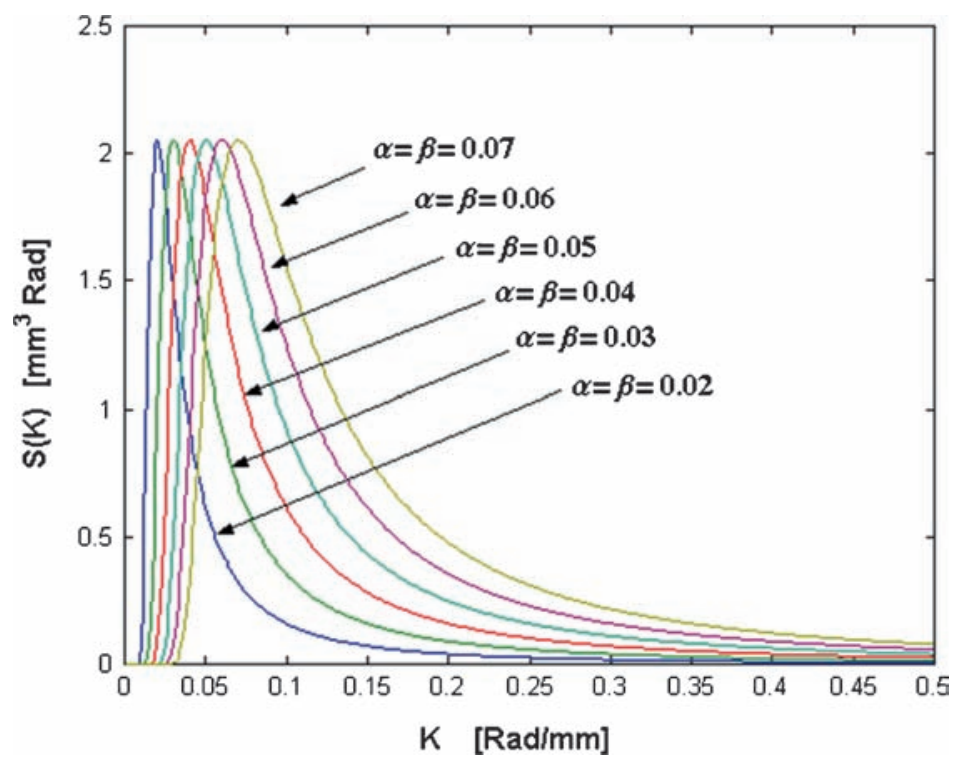

Figure 3. A family of spectra of corroded plate $\left(\Delta t_{\text {avr }}=1 \mathrm{~mm}\right.$ and $\left.\sigma=0.34 \mathrm{~mm}\right)$.

Three-dimensional geometry of corroded surface is simulated as follows (Goda 1970):

$$
\begin{aligned}
\zeta\left(x_{1}, x_{2}\right)= & \sqrt{2} \sum_{i=1}^{N_{1}} \sum_{j=1}^{N_{2}} \sqrt{2 S\left(k_{1 i}, k_{2 j}\right) \Delta k_{1} \Delta k_{2}}\left[\operatorname{Cos}\left(k_{1 i} x_{1}+k_{2 j} x_{2}+\phi_{1 i j}\right)\right. \\
& \left.+\operatorname{Cos}\left(k_{1 i} x_{1}-k_{2 j} x_{2}+\phi_{2 i j}\right)\right]
\end{aligned}
$$

where $\zeta\left(x_{1}, x_{2}\right)$ are the ordinates of points from a reference plane, $N_{1}$ and $N_{2}$ are the number of discretization of the spectrum in the $x_{1}$ and $x_{2}$ directions, respectively, $\varphi_{1 i j}$ and $\varphi_{2 i j}$ are random phase angles uniformly distributed between 0 and $2 \pi, \Delta k_{1}$ and $\Delta k_{2}$ are wave number increment in the $x_{1}$ and $x_{2}$ directions, respectively, and $k_{1 i}=i \Delta k_{1}$ and $k_{2 j}=j \Delta k_{2}$.

Parameters of $\alpha$ and $\beta$ are chosen by trial-and-error in such a way that the statistical characteristics of simulated surfaces be the same as the target surfaces. By choosing these two parameters in the given ranges, upper-cut-off wave number is determined. Having upper-cut-off wave number, and deciding on the value of number of discretization of the spectrum, $\Delta k_{1}$ and $\Delta k_{2}$ would be known. By having $\Delta k_{1}$ and $\Delta k_{2}$, spectrum at $k_{1 i}=i \Delta k_{1}$ and $k_{2 j}=j \Delta k_{2}$ are calculated. Therefore, values of $k$ changes from 0 to $k_{\mathrm{u}}$ (upper-cut-off wave number) which is less than 1 $\mathrm{rad} / \mathrm{mm}$.

Irregular thickness of a both-sided corroded plate with the same irregular surfaces at each side is determined as follows

$$
t\left(x_{1}, x_{2}\right)=t_{0}-\Delta t_{a v r}+\zeta\left(x_{1}, x_{2}\right),
$$

where $t_{0}$ is initial thickness of the plate.

Prediction of average and standard deviation of thickness diminution in any environmentstructure system was the subject of many studies in recent years. These studies are mostly done by data measurements on existing corroded structures and in some instances are supported by experiments. Based on these studies, some approximate linear, bilinear and nonlinear equations are proposed to estimate the average and standard deviation of thickness diminution of corroded 
structures. Guo et al (2008) have summarized the existing corrosion wastage models and have calculated the mean and standard deviation of corrosion wastage.

\section{Elastic buckling analysis of stiffened plate}

Interaction of different buckling modes occurs in stiffened plate. Column buckling and torsional buckling of stiffeners interact when asymmetric stiffeners are used. Interaction of plate-webtorsional buckling occurs regardless of stiffener types (figure 2). Rahbar-Ranji (2012c, 2013b) has used energy method to study interaction of different buckling modes in stiffened plate with flat-bar and tee-bar stiffeners.

Column buckling of stiffeners is considered as overall buckling of stiffened plate (Wang et al 2006) and Euler critical stress for this mode is evaluated as follows (Timoshenko \& Gere 1961):

$$
\sigma_{E}=E I \frac{\pi^{2}}{A l^{2}},
$$

where $E$ is Young's modulus, $I$ is the moment of inertia of stiffener and attached plate about neutral axis, $A$ is the cross sectional area of stiffener and attached plate, and $l$ is the length of stiffener.

\subsection{Verification of finite element model accuracy}

To check the accuracy of the FE models and to determine the appropriate mesh size, the extent of the model and boundary conditions of some preliminary un-corroded stiffened plates are analysed. Rectangular steel stiffened plates with $E=206 \mathrm{GPa}, v=0.3$, thickness of attached plate $10 \mathrm{~mm}$, breadth $600 \mathrm{~mm}$, length $3200 \mathrm{~mm}$ and four types of FB stiffeners are considered.

The extent of FE model should be appropriate to capture all buckling modes and to reduce the time of analysis. One-span double-bay model (shaded region in figure 1) is used in this work, since, it is easy to generate and yield accurate results (Rahbar-Ranji 2012c, 2013b). A uniformly distributed normal stress is applied over one end while holding the other end. Figure 4 shows the extent of FE model together with the applied load and boundary conditions. The magnitude of

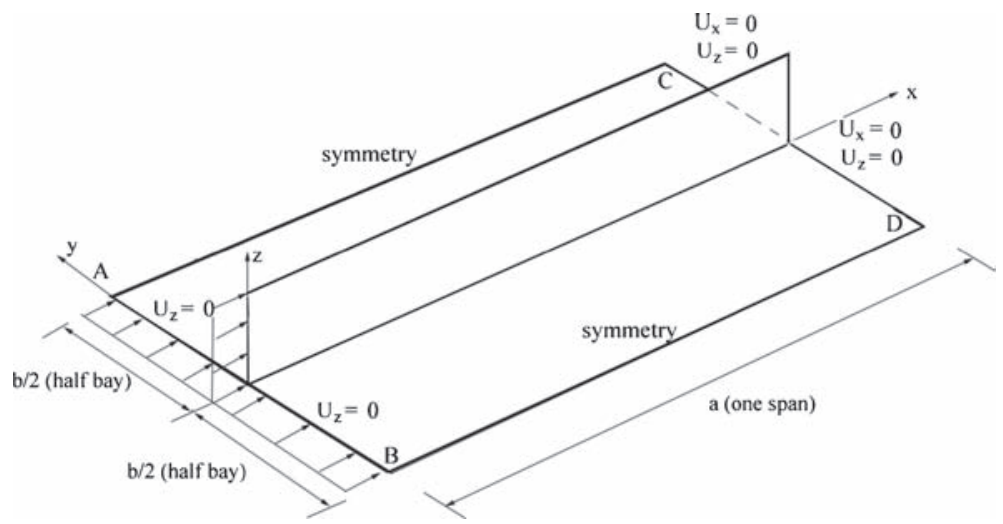

Figure 4. The extent of FE model, loading and boundary conditions. 
Table 1. Euler stress for un-corroded FB stiffened plate by different calculation methods (attached plate, $3200 \times 600 \times 10 \mathrm{~mm}$ ).

\begin{tabular}{lcccc}
\hline & \multicolumn{3}{c}{$\sigma_{\mathrm{E}}(\mathrm{MPa})$} & \\
\cline { 2 - 4 } FB type $(\mathrm{mm})$ & FEM & $\begin{array}{c}\text { Interaction of plate-web- } \\
\text { torsional buckling } \\
\text { (Rahbar-Ranji 2012c) }\end{array}$ & $\begin{array}{c}\text { Column buckling } \\
\text { Eq. (5) }\end{array}$ & Dominant buckling mode \\
\hline $100 \times 9$ & 88.64 & 218.8 & 89.7 & Column buckling \\
$120 \times 12$ & 171.0 & 237.6 & 177.1 & Column buckling \\
$140 \times 13$ & 233.10 & 248.0 & 274.9 & Plate-web-torsional buckling \\
$160 \times 14$ & 236.50 & 256.8 & 399.1 & Plate-web-torsional buckling \\
\hline
\end{tabular}

the applied load is one, and eigenvalue analysis yields a factor which is exactly Euler stress for mode one of buckling.

Table 1 shows Euler stress calculated by different methods for un-corroded stiffened plates. As can be seen, for FBs $100 \times 9 \mathrm{~mm}$ and $120 \times 12 \mathrm{~mm}$, column buckling mode is dominant mode, while for FBs $140 \times 13 \mathrm{~mm}$ and $160 \times 14 \mathrm{~mm}$ interaction of plate-web-torsional buckling mode is dominant. The deviation between FE results and Eq. (5) is about 3\% however, deviation between FE results and Rahbar-Ranji (2012c) is about 8\%. This is because analysis of interaction of plate-web-torsional buckling (Rahbar-Ranji 2012c) is based on approximate energy method, while Eq. (5) is based on equilibrium approach. Figures 5 and 6 show deformation of column buckling and interaction of plate-web-torsional buckling mode, respectively.

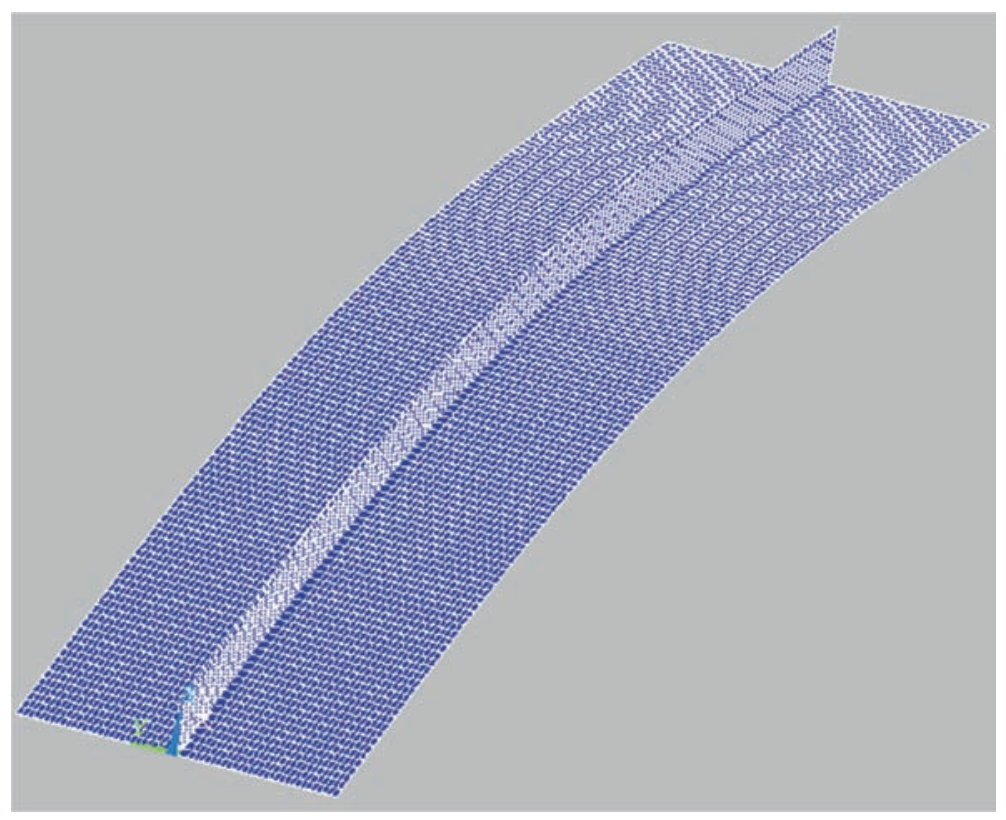

Figure 5. Column buckling mode in stiffened plate. 


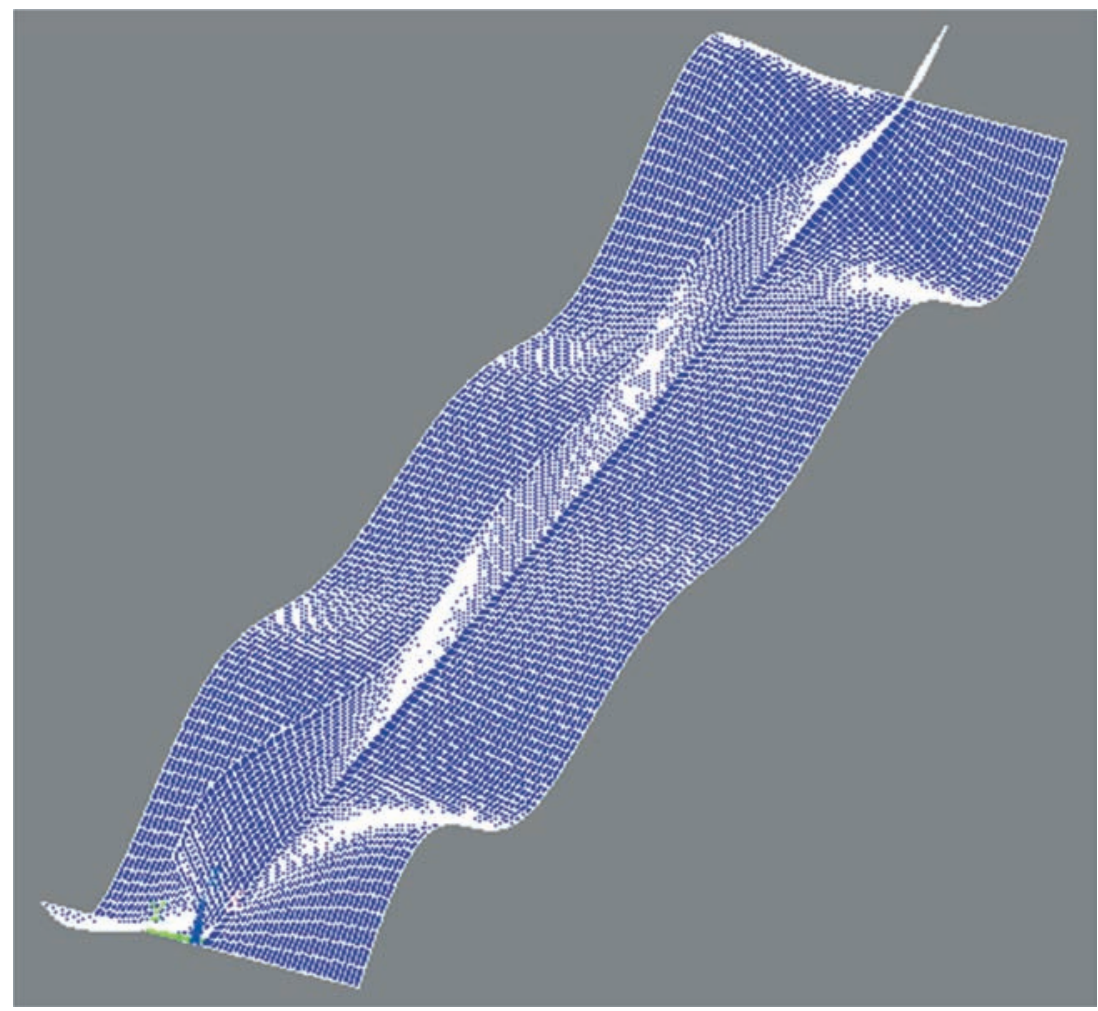

Figure 6. Interaction of plate-web-torsional buckling mode in stiffened plate.

\section{Investigated cases and discussions}

Elastic buckling analysis of a corroded stiffened plate with irregular surfaces is evaluated only on the basis of numerical analysis with FEM. A computer code in Fortran-90 is developed to generate irregular surfaces on web and attached plate based on the corresponding mean and standard deviation of thickness diminution. In this study, mean value of thickness diminution is assumed as $0.5 \mathrm{~mm}$ and standard deviation of thickness diminution as $0.1 \mathrm{~mm}$ and five different corrosion patterns (figure 7) are considered. Table 2 shows statistical characteristics of simulated surfaces together with chosen values for parameters $\alpha$ and $\beta$. As mentioned earlier, these parameters are chosen in such a way that statistical characteristics of simulated surface be the same as target values. Figure 8 shows geometry of a simulated surface with dimensions $3200 \times 300 \mathrm{~mm}$. In this figure, the distance between two adjacent points in $x$ and $y$ directions are $12 \mathrm{~mm}$ and $z$ axis shows the ordinates of points on corroded surface from average corroded surface.

Computer code, ANSYS, is used to determine elastic buckling stress of stiffened plates. Bothsided corroded plates in the web and attached plate are modelled using four-node quadrilateral shell element, SHELL63. This four-node quadrilateral shell element is capable of modelling elastic behaviour and can simulate both membrane and flexural behaviours. In addition, it has three rotational and three translational degrees of freedom per node. Figure 9 shows FE model of 


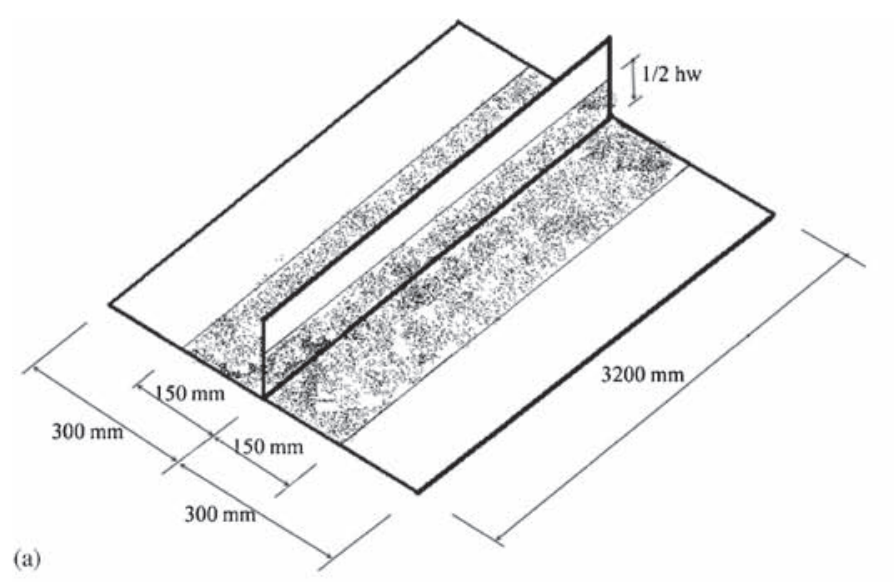

(b)
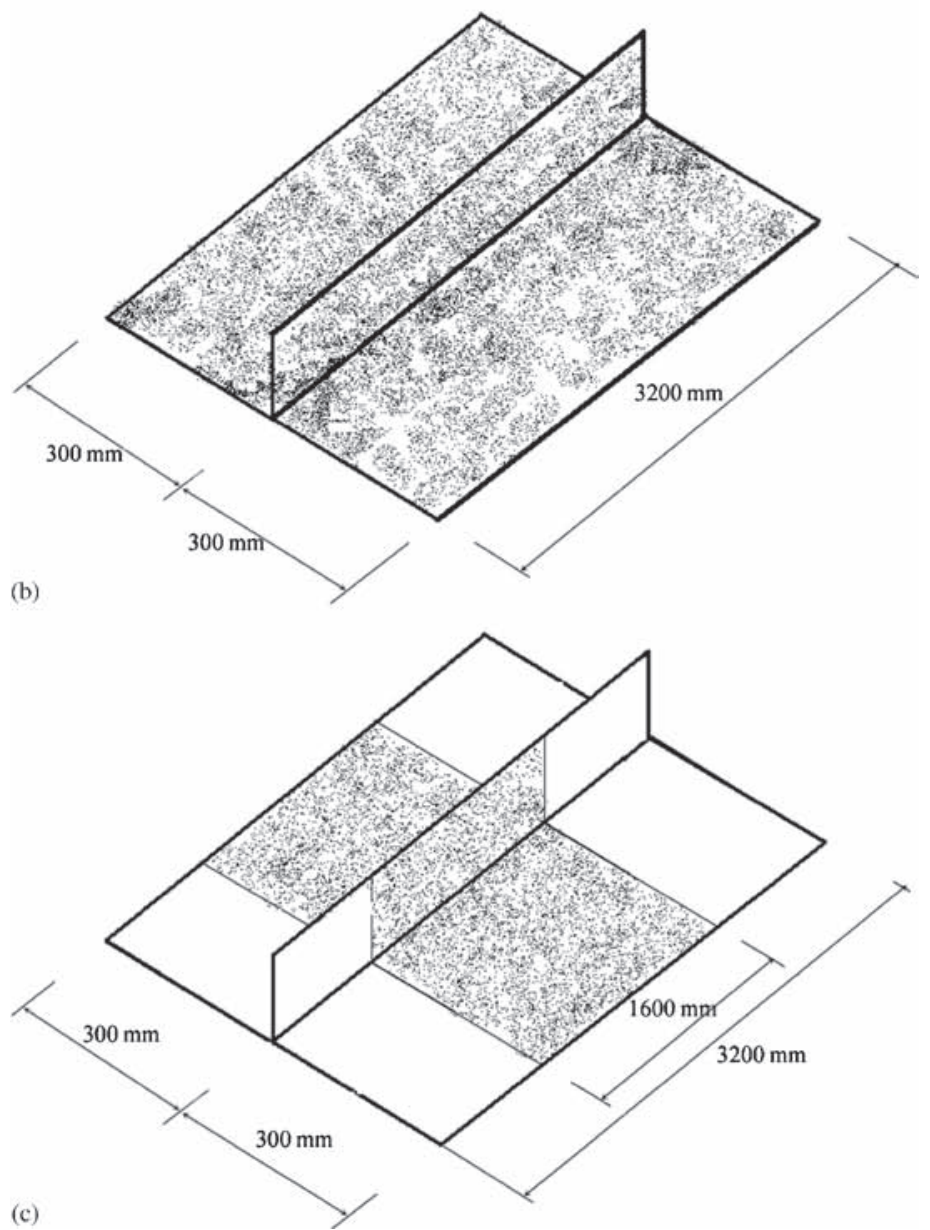

Figure 7. Corrosion patterns considered in this work. (a) Corrosion pattern no.1, corrosion concentrate at connection line of stiffener to the attached plate. (b) Corrosion pattern no.2, plate and stiffener fully corroded. (c) Corrosion pattern no.3, corroded area at mid span. (d) Corrosion pattern no.4, corroded area at mid bay. (e) Corrosion pattern no.5, plate is fully corroded. 

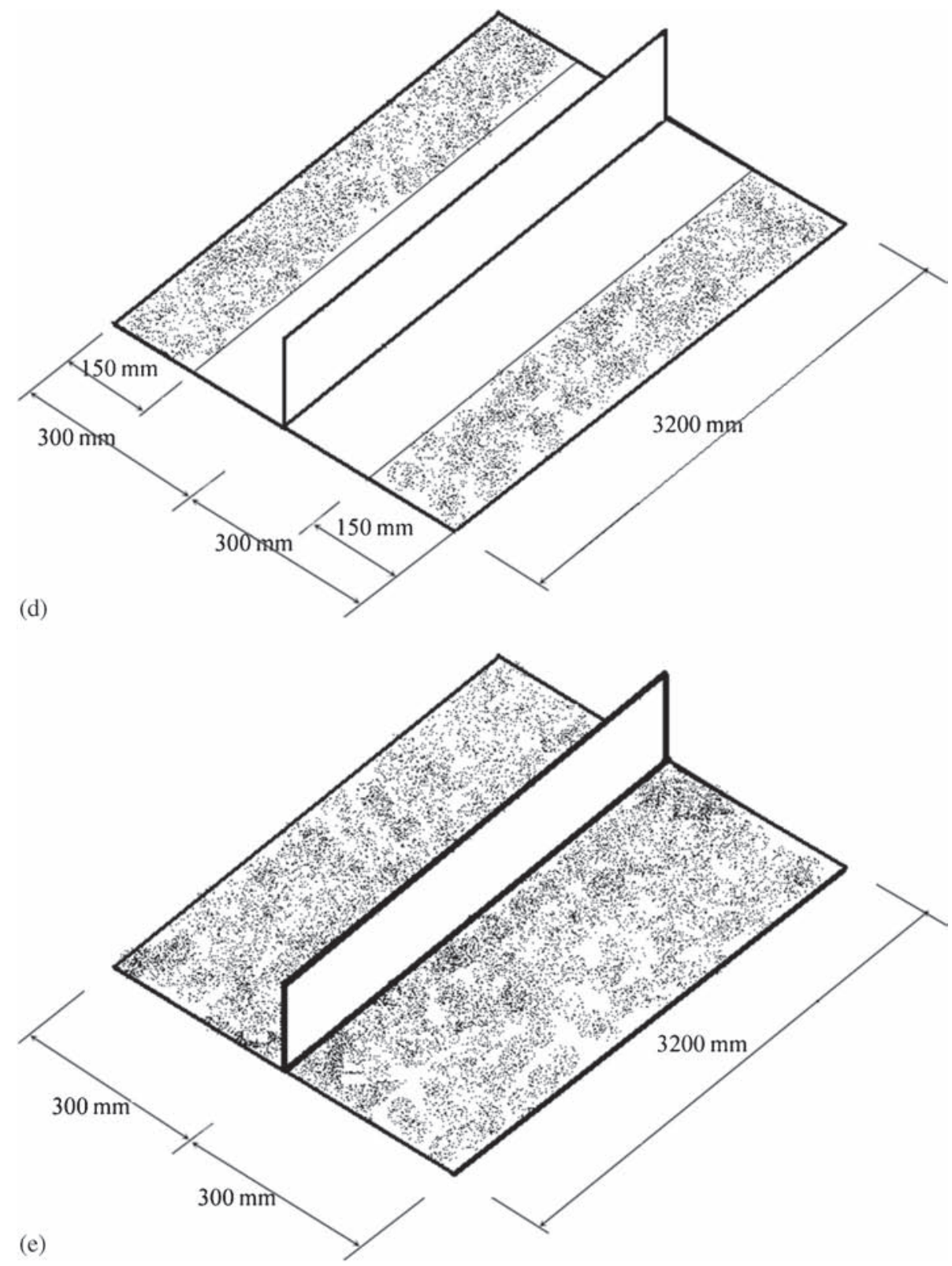

Figure 7. (continued)

a stiffened plate with both sided corroded surfaces. Since shell elements are used to model corroded plates, irregular surfaces are modelled using variable thickness at each node. This means that thickness of plate varies from node to node. The thickness of each node is determined based on ordinates of points on both sides of simulated surface using Eq. (4). The size of meshes is decided when running the prepared code in Fortran-90 to generate irregular surfaces. In this study, the distance between nodes in each side is taken less than $10 \mathrm{~mm}$. 
Table 2. Statistical characteristics of simulated surfaces (target surface $\Delta \mathrm{t}_{\mathrm{avr}}=0.5 \mathrm{~mm}, \sigma=0.1 \mathrm{~mm}$ ).

\begin{tabular}{lcccc}
\hline $\begin{array}{l}\text { Dimensions of simulated } \\
\text { surface }(\mathrm{mm})\end{array}$ & $\alpha$ & $\beta$ & $\Delta \mathrm{t}_{\mathrm{avr}}(\mathrm{mm})$ & $\sigma(\mathrm{mm})$ \\
\hline $1600 \times 100$ & 0.02 & 0.02 & 0.528 & 0.096 \\
$1600 \times 120$ & 0.02 & 0.02 & 0.525 & 0.098 \\
$1600 \times 140$ & 0.02 & 0.02 & 0.521 & 0.099 \\
$1600 \times 160$ & 0.02 & 0.02 & 0.523 & 0.100 \\
$1600 \times 300$ & 0.02 & 0.02 & 0.541 & 0.104 \\
$3200 \times 50$ & 0.02 & 0.04 & 0.518 & 0.095 \\
$3200 \times 60$ & 0.04 & 0.02 & 0.499 & 0.100 \\
$3200 \times 70$ & 0.03 & 0.03 & 0.519 & 0.106 \\
$3200 \times 80$ & 0.02 & 0.03 & 0.527 & 0.101 \\
$3200 \times 100$ & 0.02 & 0.03 & 0.529 & 0.105 \\
$3200 \times 120$ & 0.025 & 0.02 & 0.504 & 0.098 \\
$3200 \times 140$ & 0.025 & 0.02 & 0.507 & 0.100 \\
$3200 \times 150$ & 0.025 & 0.02 & 0.503 & 0.095 \\
$3200 \times 160$ & 0.025 & 0.02 & 0.511 & 0.102 \\
$3200 \times 300$ & 0.02 & 0.02 & 0.532 & 0.101 \\
\hline
\end{tabular}

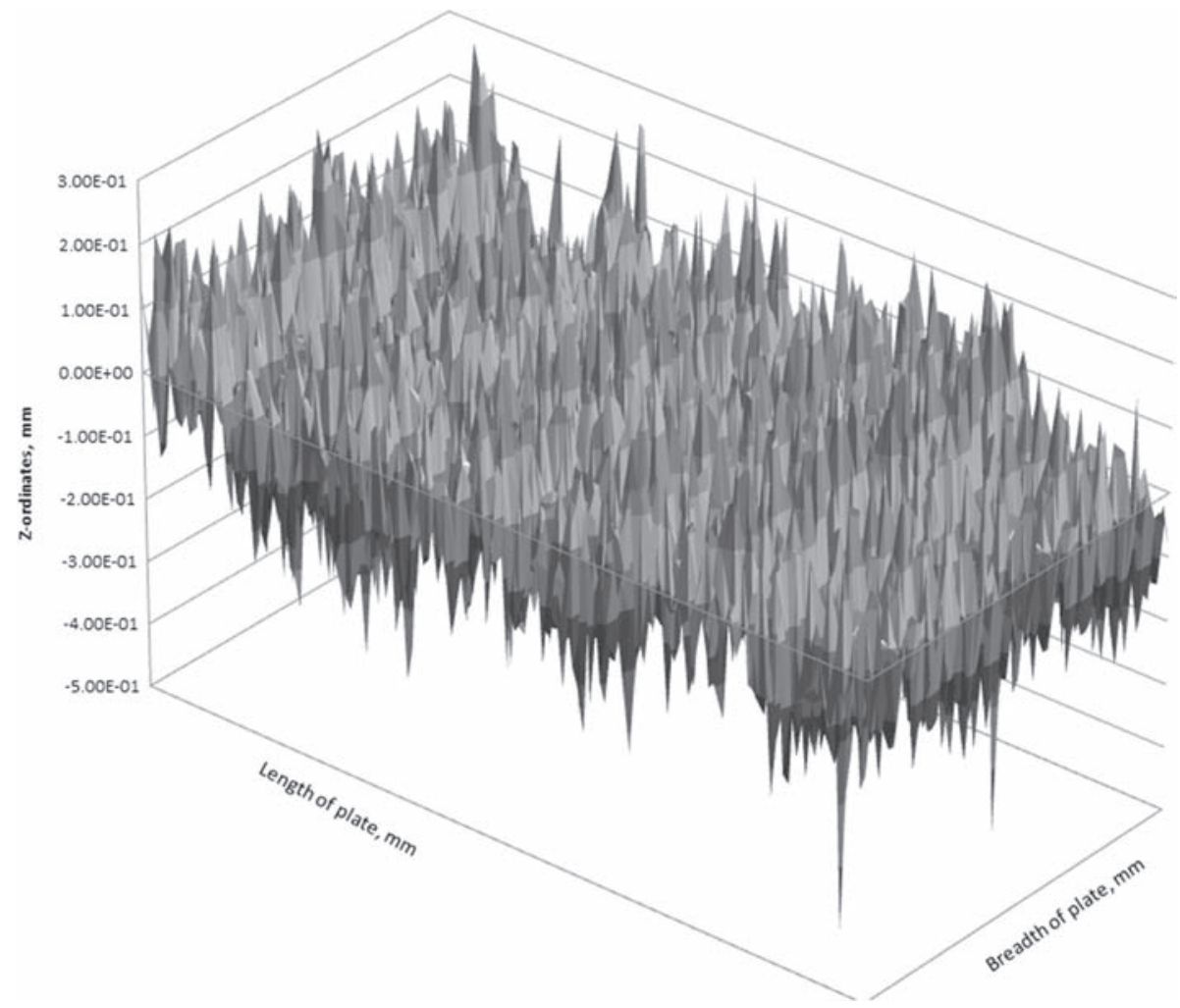

Figure 8. Simulated surface with dimensions $3200 \times 300 \mathrm{~mm}\left(\Delta \mathrm{t}_{\mathrm{avr}}=0.5 \mathrm{~mm}\right.$ and $\left.\sigma=0 . l \mathrm{~mm}\right)$. 


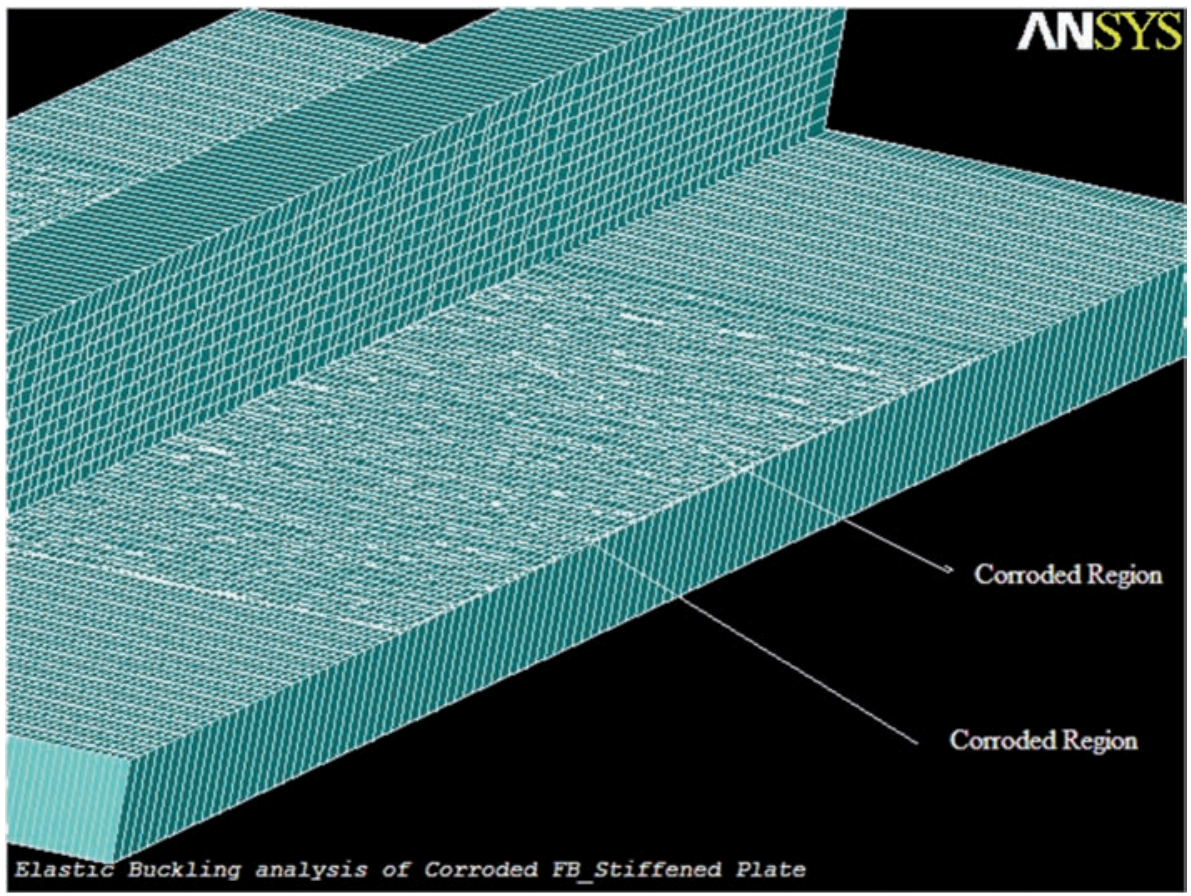

Figure 9. FE model of corroded FB-stiffened plate (shell elements are magnified).

Table 3. Euler stress of corroded FB-stiffened plate (Attached plate, $3200 \times 600 \times 10 \mathrm{~mm}$ ).

\begin{tabular}{llccc}
\hline $\begin{array}{l}\text { Corrosion } \\
\text { pattern }\end{array}$ & $\begin{array}{c}\text { Flat bar } \\
(\mathrm{mm})\end{array}$ & $\begin{array}{c}\text { Euler stress } \\
(\mathrm{MPa})\end{array}$ & Dominant buckling mode & $\begin{array}{c}\text { Reduction } \\
\text { parameter }\end{array}$ \\
\hline No.1 & $100 \times 9$ & 90.09 & Column buckling & 1.02 \\
& $120 \times 12$ & 173.78 & Column buckling & 1.02 \\
& $140 \times 13$ & 208.11 & Plate-web-torsional buckling & 0.89 \\
No.2 & $160 \times 14$ & 223.26 & Plate-web-torsional buckling & 0.94 \\
& $100 \times 9$ & 88.37 & Column buckling & 0.99 \\
& $120 \times 12$ & 172.03 & Column buckling & 1.01 \\
& $140 \times 13$ & 213.29 & Plate-web-torsional buckling & 0.92 \\
No.3 & $160 \times 14$ & 211.56 & Plate-web-torsional buckling & 0.89 \\
& $100 \times 9$ & 87.53 & Column buckling & 0.98 \\
& $120 \times 12$ & 169.77 & Column buckling & 0.99 \\
No.4 & $140 \times 13$ & 220.42 & Plate-web-torsional buckling & 0.95 \\
& $160 \times 14$ & 224.34 & Plate-web-torsional buckling & 0.95 \\
& $100 \times 9$ & 90.24 & Column buckling & 1.02 \\
& $120 \times 12$ & 173.43 & Column buckling & 1.01 \\
No.5 & $140 \times 13$ & 207.23 & Plate-web-torsional buckling & 0.89 \\
& $160 \times 14$ & 207.96 & Plate-web-torsional buckling & 0.88 \\
& $100 \times 9$ & 91.89 & Column buckling & 1.04 \\
& $120 \times 12$ & 176.57 & Column buckling & 1.03 \\
& $140 \times 13$ & 211.40 & Plate-web-torsional buckling & 0.91 \\
& $160 \times 14$ & 214.28 & Plate-web-torsional buckling & 0.91 \\
\hline
\end{tabular}




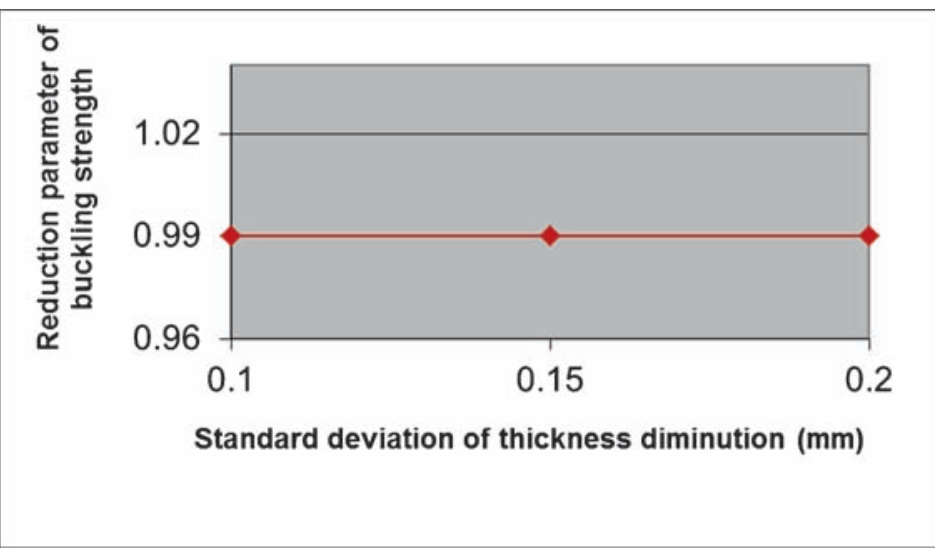

Figure 10. Reduction parameter of buckling strength due to corrosion for plate stiffened with FB $120 \times 12$ $\mathrm{mm}$, average thickness diminution $0.5 \mathrm{~mm}$ and corrosion pattern no.3.

Euler stress for stiffened plates with irregular surfaces are calculated and compared with Euler stress of un-corroded plates. For each case a reduction parameter is defined as follows

$$
R=\frac{\sigma_{E-C o r r}}{\sigma_{E-U n c o r r}} .
$$

Table 3 gives Euler stresses and reduction parameters for stiffened plates with different corrosion patterns. It can be seen that reduction of buckling strength is not noticeable when column buckling is dominant mode of buckling. When interaction of plate-web-torsional buckling is dominant mode of buckling, corrosion can reduce buckling strength of stiffened plate by as much as $12 \%$. Also it can be concluded that corrosion pattern has influence on reduction of buckling strength, but not significantly. When corrosion concentrates at mid span (corrosion pattern no.3), reduction of buckling strength for column buckling is more than when it occurs at full length.

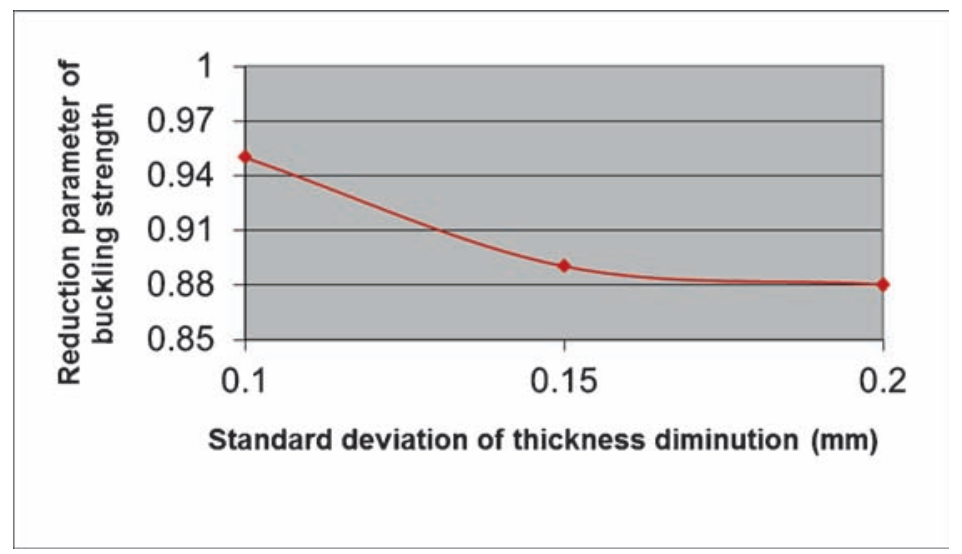

Figure 11. Reduction parameter of buckling strength due to corrosion for plate stiffened with FB $140 \times 13$ $\mathrm{mm}$, average thickness diminution $0.5 \mathrm{~mm}$ and corrosion pattern no.3. 


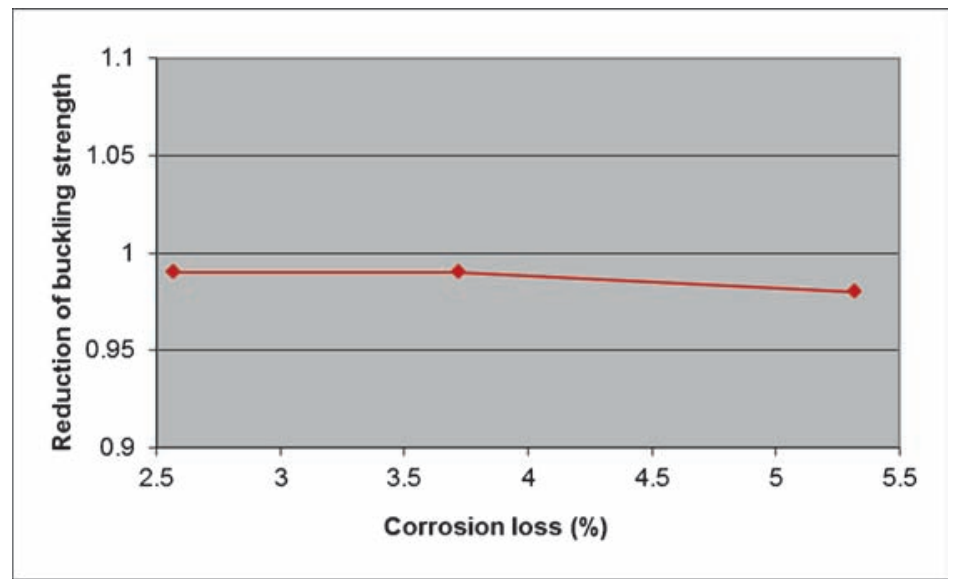

Figure 12. Reduction parameter of buckling strength due to corrosion for plate stiffened with FB120 $\times 12$ $\mathrm{mm}$ and standard deviation $0.1 \mathrm{~mm}$, corrosion pattern no.3.

For interaction of plate-web-torsional buckling, reduction of buckling strength is higher when corrosion concentrated at mid bay (corrosion pattern no.4), rather than at edges or mid span.

To investigate the effect of roughness of surface on reduction parameter of buckling strength, standard deviation of thickness diminution is changed. Figures 10 and 11 show reduction of buckling strength as a function of standard deviation for stiffened plate with FB $120 \times 12 \mathrm{~mm}$ (column buckling mode) and FB $140 \times 13 \mathrm{~mm}$ (interaction of plate-web-torsional buckling mode), respectively, and corrosion pattern no.3. As can be seen, roughness of surface has no influence on reduction of buckling strength for column buckling mode, however, for interaction of plate-web-torsional buckling mode, generally speaking, by increasing roughness of surface, buckling strength decreases.

Figures 12 and 13 show variation of reduction parameter as a function of corrosion loss in corrosion pattern no. 3 for stiffened plate with FBs $120 \times 12 \mathrm{~mm}$ and $140 \times 13 \mathrm{~mm}$, respectively.

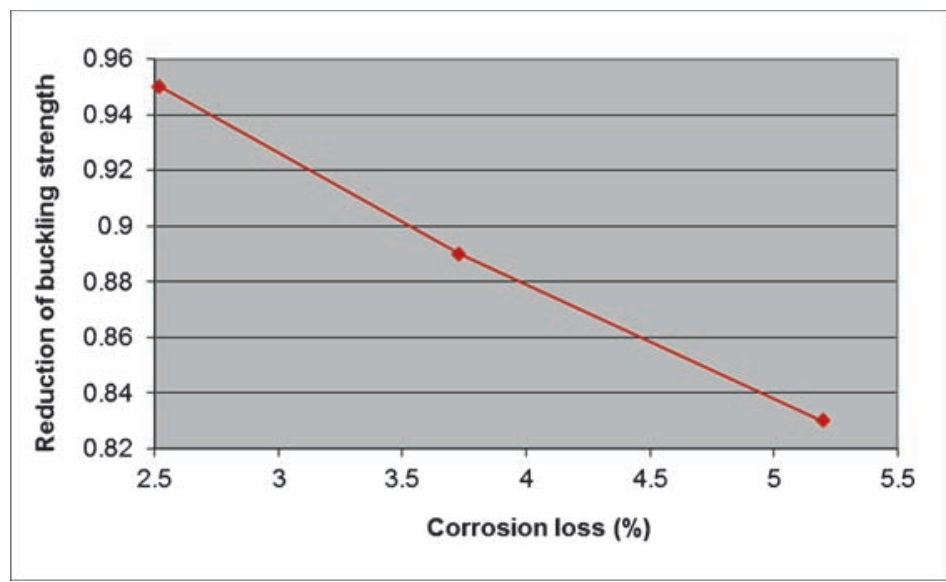

Figure 13. Reduction parameter of buckling strength due to corrosion for plate stiffened with FB $140 \times 13$ $\mathrm{mm}$ and standard deviation $0.1 \mathrm{~mm}$, corrosion pattern no.3. 
As can be seen, buckling strength reduces as corrosion loss increases, but its effect is more noticeable when interaction of plate-web-torsional buckling is dominant mode of buckling.

\section{Conclusions}

There is little study on strength of corroded stiffened plate with irregular surfaces. Eigenvalue analysis by using FEM is used for calculation of Euler critical stress of corroded stiffened plates with both sided irregular surfaces. A reduction parameter is introduced as a ratio of Euler stress of corroded stiffened plate with irregular thickness at each node over Euler stress of un-corroded stiffened plate. Influential parameters are studied and it was found that when column buckling is dominant mode, reduction of buckling strength due to corrosion is not noticeable. When interaction of plate-web-torsional buckling is dominant mode, reduction of buckling strength is significant. Roughness of surface, amount of corrosion loss and corrosion pattern have effect on reduction parameter. By increasing roughness of surface and amount of corrosion loss, buckling strength reduces, however their effects are more noticeable in plate-web-torsional buckling mode. When corrosion concentrates at full length in the mid bay, reduction of buckling strength is higher than when corrosion occurs at whole area of plate and stiffener.

\section{References}

ANSYS Version 5.61999 Canonsburg, PA, USA

Goda Y 1970 Numerical experiments on wave statistics with spectral simulation. Rep. Port Harbor Res. Inst. 9(3): 3-57

Guo J, Wang G, Ivanov L and Perakis N 2008 Time varying ultimate strength of aging tanker deck plate considering corrosion effect. Mar. Struct. 21: 402-419

Huang Y, Zhang Y, Liu G and Zhang Q 2010 Ultimate strength assessment of hull structural plate with pitting corrosion damnification under biaxial compression. Ocean Eng. 37: 1503-1512

Nakai T, Matsushita H and Yamamoto N 2006 Effect of pitting corrosion on the ultimate strength of steel plates subjected to in-plane compression and bending. J. Mar. Sci. Technol. 11(1): 52-64

Oszvald K and Dunai L 2010 Effect of corrosion on the buckling of steel angle elements. 8th fib PhD Symposium in Kgs. Lyngby, Denmark

Rahbar-Ranji A 2001 Stress analysis of a randomly undulated plate due to corrosion in marine structures. Ph.D. Thesis, Yokohama National University, Department of Naval Architecture, Japan

Rahbar-Ranji A 2012a Plastic collapse load of corroded steel plates. Sadhana-Academy Proceed. Eng. Sci. 37(3): 341-349

Rahbar-Ranji A 2012b Ultimate strength of corroded steel plates with irregular surfaces under in-plane compression. Ocean Eng. 54: 261-269

Rahbar-Ranji A 2012c Elastic buckling analysis of longitudinally stiffened plates with flat-bar stiffeners. Ocean Eng. 58: 48-59

Rahbar-Ranji A 2013a Elastic buckling strength of corroded steel plates. Sadhana-Academy Proceed. Eng. Sci. 38(1): 89-99

Rahbar-Ranji A 2013b Elastic coupled buckling analysis in stiffened plates with T-bar stiffeners. Proc. IMechE Part C: J. Mech. Eng. Sci. 227(6): 1135-1149 DOI:10.1177/0954406212458076

Rahbar-Ranji A 2014a Buckling Analysis of Partially Corroded Steel Plates with Irregular Surfaces. Sadhana-Academy Proceed. Eng. Sci. 39(2): 511-524

Rahbar-Ranji A 2014b Elastic tripping analysis of corroded stiffeners in stiffened plate with irregular surfaces. J. Mech. Sci. Technol. 28(9): 3629-3636 DOI:10.1007/s12206-014-0824-9

SSC-394 1997 Strength assessment of pitted plate panels, ship structural committee 
Timoshenko S P and Gere J M 1961 Theory of elastic stability. $2^{\text {nd }}$ ed, Eng. Societies Monograph NY: McGraw Hill

Wang G, Spencer J and Sun H 2005 Assessment of corrosion risks to aging ships using an experience database. J. Offshore Mech. Arctic Eng. 127(2): 167-174

Wang C L E, Grondin G Y and Elwi A E 2006 Interaction buckling failure of stiffened steel plates. University of Alberta Structural Engineering report No. 264 